\title{
An MDOE Assessment of Nozzle Vanes for High Bypass Ratio Jet Noise Reduction
}

\author{
Brenda Henderson ${ }^{*}$ and Thomas Norum ${ }^{\dagger}$ \\ NASA Langley Research Center, Hampton, VA, 23681 \\ James Bridges ${ }^{\ddagger}$ \\ NASA Glenn Research Center, Cleveland, OH, 44135
}

\begin{abstract}
The effect of airfoil-shaped vanes placed in the fan stream of a BPR 8 coannular nozzle model system on the resulting jet noise was investigated. The experiments used a Modern Design of Experiments approach to investigate the impact of a range of vane parameters on the noise reduction achieved at representative takeoff conditions. The experimental results showed that the installation of the vanes decreased low frequency noise radiation in the downstream peak-noise direction and increased high frequency noise in the upstream direction. Results also showed that improper selection of the vane configuration resulted in increased low frequency noise radiation in the upstream direction. Large angles of attack are shown to reduce noise near the peak jet noise angle and increase noise in the upstream direction. The MDOE analysis yields an optimum design that minimizes perceived noise levels. Limited data taken with a BPR 5 nozzle system showed that the vanes result in better effective perceived noise reduction for lower bypass ratio nozzles than for the BPR 8 model.
\end{abstract}

\section{Introduction}

$\mathrm{T}$ He development of effective noise reduction technologies for high bypass ratio (BPR $\geq 8$ ) turbo-fan engines continues to draw interest as airport capacity increases. A common noise reduction approach is to enhance mixing through mechanical chevrons ${ }^{1,2,3}$ or various types of fluidic injection ${ }^{4,5}$. A very different approach originally proposed by Papamoschou ${ }^{6}$ involves moving the fan stream relative to the core stream with vanes as shown in Fig. 1. Introducing the vanes increases the fan stream potential core length on the observation side of the jet and reduces the convective Mach number of the instability waves which leads to reduced low frequency acoustic radiation. The experiment described here uses a Modern Design of Experiments (MDOE) approach to investigate the effective

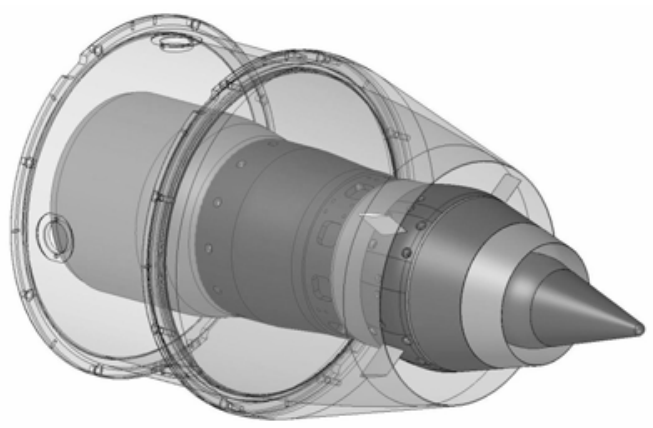

Figure 1. A schematic of the BPR 8 nozzle system with vanes used in the experiments. perceived noise levels resulting from the application of the vane technology to a BPR 8 model system.

Jet mixing noise is often divided into two source types: noise associated with fine-scale turbulence and noise associated with large-scale structures in the jet ${ }^{7}$. The large scale-structures have been modeled as instability waves with spatially varying amplitudes. When the amplitude is not constant ${ }^{8}$, acoustic radiation occurs for a range of wave numbers even when the convective Mach number is subsonic. The range of wave numbers for which acoustic radiation occurs is reduced when the convective Mach number is reduced resulting in a reduction of acoustic radiation from this type of source mechanism.

Experiments have shown that it is possible to extend the length of the secondary potential core beyond that of the primary potential core through the use of vanes ${ }^{6}$. Results from scale model tests show that the introduction of vanes to the fan stream of dual flow nozzles reduces noise at all frequencies in the downstream direction of the jet ${ }^{9}$. Parametric studies using two vane and four vane configurations ${ }^{10}$ have shown that some noise reduction over that of the coaxial nozzles can also be achieved at $90^{\circ}$ when four vanes are used.

\footnotetext{
${ }^{*}$ Researcher, Aeroacoustics Branch, MS 166, Hampton, VA 23681.

${ }^{\dagger}$ Reseacher, Aeroacoustics Branch, MS 166, Hampton, VA 23681.

${ }^{\ddagger}$ Researcher, Acoustics Branch, MS 54-3, Cleveland, OH 44135.
} 
In this investigation, a parametric study using MDOE techniques to investigate the impact of vane configuration on the resulting jet noise radiation was performed. The vane parameters important to the reduction of perceived noise levels are identified and models are given for the prediction of sound pressure levels at the peak perceived noise angle and angles near the peak jet noise angle.

\section{MDOE Design}

Using MDOE techniques, the change in the output or response (1/3 octave band levels in this study) of a system is determined as a function of the change in the input to the system (the vane angle of attack for example). Any number of factors (parameters) can be investigated as the system input, and the relative importance of each factor to changing the system output will be determined as a result of the analysis. In a full factorial design, every combination of the factors and factor levels (values chosen for each parameter) are tested in a random order. Randomization is a necessary part of MDOE investigations as it reduces the impact of systematic errors on the experimental results. Other types of designs can be used to reduce the required number of test points but the inherent weaknesses in these approaches make other designs unattractive for the investigation presented here.

Screening MDOE designs often test only two levels of each factor (a high and low vane angle of attack for instance). These screening designs use linear regression to obtain a model describing the change in the system response for a change in any of the input factors. Factor interactions that significantly impact the system response are also represented in this model. It is not possible to quantify curvature in the system response with a two level design, which means that pure quadratic terms (the square of the change in the vane angle of attack for example) are not present in the model. However, by adding one additional point to the test matrix (a center point in the design) and computing the difference in the response predicted by the model and that measured in the experiment, systems with significant curvature can be identified. .

Modern Design of Experiments techniques use analysis of variance to separate system response changes associated with experimental error and those associated with changes in the system input (main effects). The analysis can also compensate for blocking effects, which are systematic errors that cannot be eliminated by randomizing the test matrix. An example of blocking occurs when it is not possible to take the test data in one day.

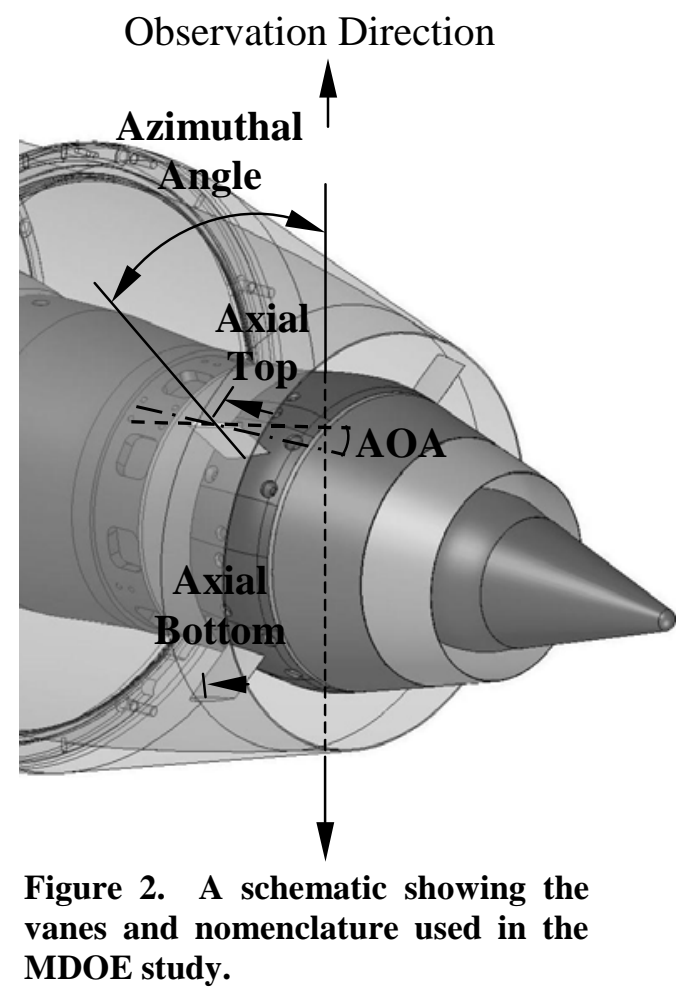
A block of data will then result from each day of testing. The data taken on one day could be shifted (or biased) from the data taken on a different day. Another advantage of the MDOE analysis is that it computes a level of confidence to the relevance of all factors and their interactions on the system response. A two level, full factorial design (including a center point) was chosen for the study presented here. Results from prescreening computational fluid dynamics (CFD) were used to identify configurations and factor levels that did not lead to flow separation or shocks over the vanes. The CFD results were also used to eliminate factors from the MDOE design that did not appear to have a significant impact on the jet plume.

A vane configuration consisted of a given value for each of the four chosen factors. The factors are shown schematically in Fig. 2, and the chosen range of each factor is tabulated in Table 1. The factors are the airfoil angle of attack (the same for all airfoils), the azimuthal angle (the acute angle between the microphone, or observation, axis and the airfoil, also the same for all airfoils), the axial location for the two airfoils on the observation side of the jet (denoted "Axial Location - Top" in Table 1), and the axial location for the two airfoils on the other side of the jet (denoted "Axial Location - Bottom” in Table 1). The airfoil axial location is defined as the distance from the fan nozzle trailing edge to the center of the vane, measured as a fraction of the airfoil chord length. All possible high and low levels for each of the four factors leads to 16 possible combinations. The addition of a center point resulted in testing 17 different vane configurations for a complete MDOE design.

The center point of the design is shown schematically in Fig. 3 (where the axis for the fourth factor is necessarily missing due to the limits of a three dimensional sketch). The configuration for the center point had a $7.5^{\circ}$ angle of 
attack, a $60^{\circ}$ azimuthal angle, and axial locations for both top and bottom airfoil sets equal to 0.5 . The center point

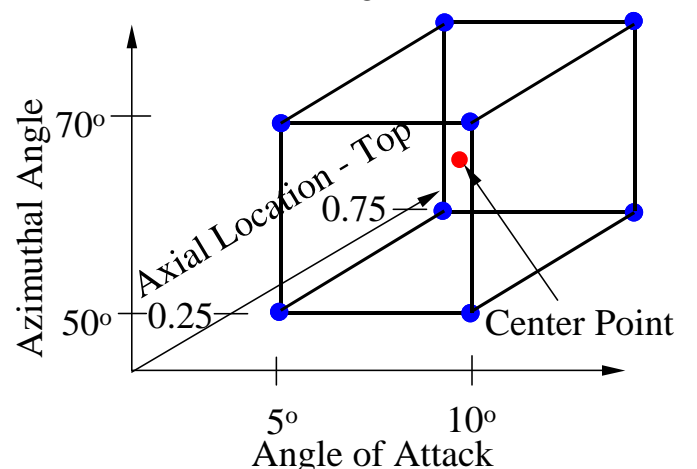

Figure 3. A schematic showing three of the four factors in the MDOE design. The blue points are the design points shown in Table 1 and the red point is the center point. was used to identify curvature in the system response and to quantify experimental error. It was replicated twice in each of the four data blocks, yielding a total of 24 test points at the same operating condition

Table 1. MDOE

\begin{tabular}{|l|c|c|}
\hline \multicolumn{1}{|c|}{ Parameter } & Low Level & High Level \\
\hline Angle of Attack & $5^{\circ}$ & $10^{\circ}$ \\
Azimuthal Angle & $50^{\circ}$ & $70^{\circ}$ \\
Axial Location - Top & 0.25 & 0.75 \\
Axial Location - Bottom & 0.25 & 0.75 \\
\hline
\end{tabular}

The system responses selected for the MDOE analysis were the levels in the one-third octave bands that significantly impacted the perceived noise levels. The selected responses, discussed in more detail in Section IV, were a function of operating condition and flight Mach number.

\section{Experimental Approach}

The experiments were performed in the Aero-Acoustic Propulsion Laboratory (AAPL) at the NASA Glenn

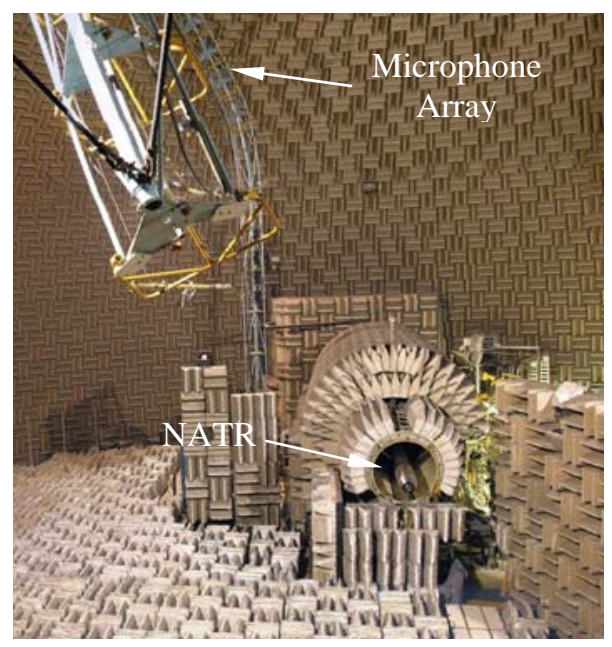

Figure 4. A photograph of the AeroAcoustic Propulsion Laboratory (AAPL) showing the Nozzle Acoustic Test Rig (NATR). Research Center shown in Fig. 4. The AAPL is a $20 \mathrm{~m}$ radius geodesic dome treated with acoustic wedges. The AAPL contains the Nozzle Acoustic Test Rig (NATR), a dual stream jet engine simulator surrounded by a 53" diameter air stream used to simulate forward flight Mach numbers up to 0.32. The jet engine simulator can replicate real temperatures and pressures of most commercial turbofan engines. See Bridges ${ }^{12}$ for a detailed description of the NATR.

For the MDOE study, a bypass ratio (BPR) 8, externally plugged, coannular nozzle model was used. The core and fan nozzle exit diameters were 4.87 and 9.63 in, respectively, and their exit areas were 8.42 and $32.72 \mathrm{in}^{2}$, respectively. One vane configuration was also investigated with a BPR 5 nozzle model system that used the same fan nozzle and plug as the BPR 8 model but had a 5.18 in diameter core nozzle with an exit area of $10.29 \mathrm{in}^{2}$. The corresponding fan nozzle area was $28.94 \mathrm{in}^{2}$.

Vanes in the shape of NACA 0012 airfoils with chord lengths equal to 1.32 in were mounted on the core stream center body as shown in Figs. 1 and 2. The airfoils were designed so they would span the entire fan stream when the model was at takeoff temperature conditions. Table 2 shows the nozzle pressure ratios (NPR), total temperatures $\left(\mathrm{T}_{\mathrm{T}}\right)$ and the tunnel Mach numbers used in the experiments. Only the data taken at the takeoff conditions will be

Table 2. Experimental Test Conditions

\begin{tabular}{|l|r|rr|r|r|r|r|}
\hline Condition & $\begin{array}{c}\text { NPR } \\
\text { Fan }\end{array}$ & \multicolumn{1}{|c|}{$\begin{array}{c}\mathbf{T}_{\mathrm{T}}\left({ }^{\mathbf{0}} \mathrm{R}\right) \\
\text { Fan }\end{array}$} & $\begin{array}{c}\text { NPR } \\
\text { Core }\end{array}$ & $\begin{array}{c}\mathrm{T}_{\mathrm{T}}\left({ }^{\mathbf{0}} \mathrm{R}\right) \\
\text { Core }\end{array}$ & $\begin{array}{c}\text { Mach 0.2 } \\
\text { Tunnel }\end{array}$ & $\begin{array}{c}\text { Static } \\
\text { Tunnel }\end{array}$ & $\begin{array}{c}\text { Model } \\
\text { (BPR) }\end{array}$ \\
\hline Takeoff & 1.62 & 640 & 1.42 & 1498 & $\checkmark$ & $\checkmark$ & 8 \\
Cutback & 1.46 & 640 & 1.27 & 1376 & $\checkmark$ & & 8 \\
Approach & 1.26 & 640 & 1.13 & 1241 & $\checkmark$ & & 8 \\
Takeoff & 1.73 & 640 & 1.51 & 1420 & $\checkmark$ & $\checkmark$ & 5 \\
\hline
\end{tabular}
shear layer effects using Ahuja, Testor, and Tanna ${ }^{13}$ correction, Dopplar shifted, corrected to a standard day ${ }^{14}$, propagated to a sideline distance of $1500 \mathrm{ft}$, and scaled using a scale factor of 8. 


\section{Results}

Results from detailed MDOE analyses for the BPR5 nozzle system at the takeoff condition both at a flight Mach number of 0.2 and at static conditions will be presented. For each of the two tunnel conditions, effective perceived noise levels (EPNL) were calculated for each test point. The airfoil configuration having the lowest EPNL was designated the "best" airfoil configuration and the configuration with the highest EPNL the "worst". The configuration with no airfoils present was designated the baseline.

\section{A. MDOE Results for Takeoff Conditions and a Flight Mach Number of 0.2}

The directivities of the perceived noise levels (PNL) for the "best" and "worst" airfoil configurations and for the baseline are shown in Fig. 5. Introduction of the vanes increases the PNL at upstream angles (below $110^{\circ}$ ) and decrease the PNL at downstream angles (above $130^{\circ}$ ). There is a decrease in perceived noise from that of the baseline nozzle in the peak jet-noise direction (near $140^{\circ}$ ) for all airfoil configurations. For some airfoil configurations, this decrease in the peak jet noise direction overcomes the increase at the lower angles and results in

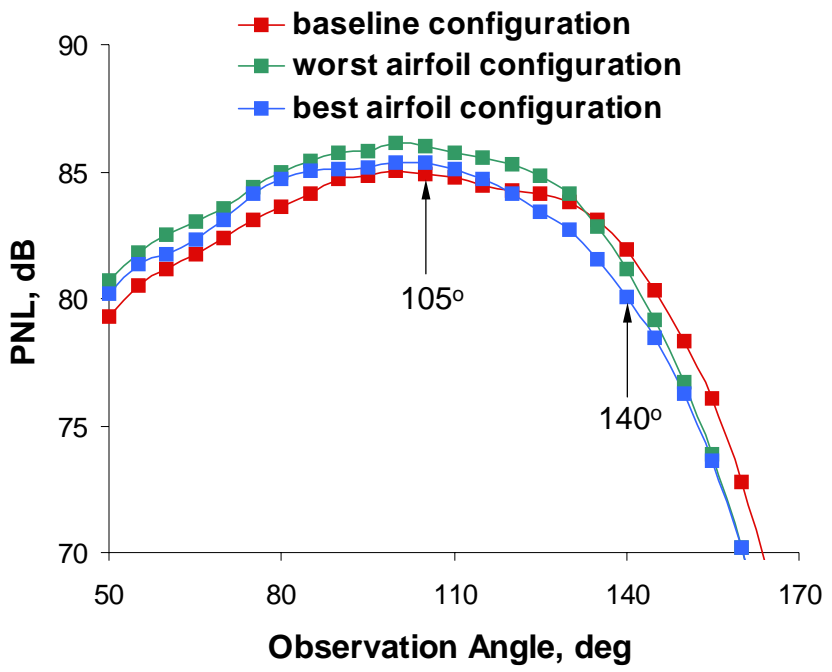

Figure 5. The perceived noise levels for the best (lowest EPNL) and worst (highest EPNL) airfoil configuration and the baseline nozzles (no airfoils).

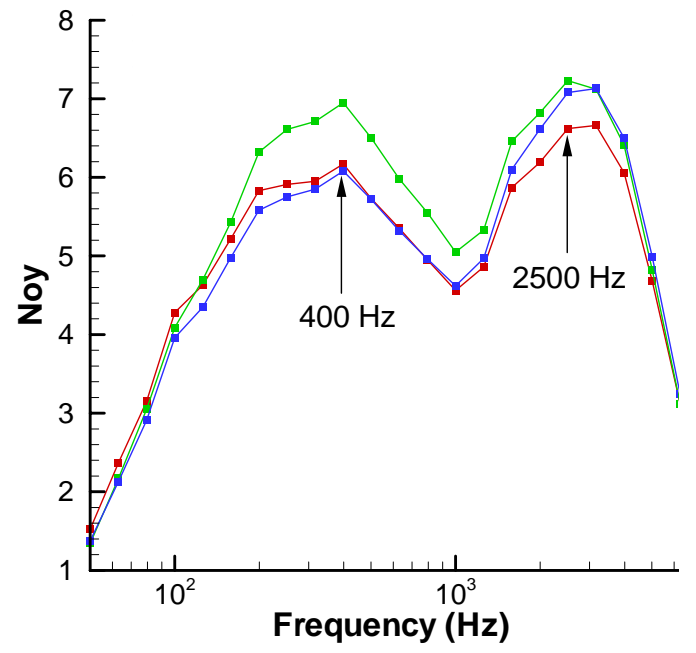

(a) a lower EPNL than the baseline. The best airfoil configuration tested resulted in a 0.4 EPNdB reduction in EPNL from the baseline.

The frequencies that most influence the PNL differences can be seen from comparisons of noy spectra. These spectra are given in Fig. 6 for the three configurations of Fig. 5 at angles near the peak PNL $\left(105^{\circ}\right)$ and the peak jet noise $\left(140^{\circ}\right)$. At both angles the spectra show humps at both high frequency $(2500 \mathrm{~Hz})$ and low frequency $(400 \mathrm{~Hz}$ or $200 \mathrm{~Hz}$ ). At the high frequency humps, the noy levels are about the same for the best and worst configurations at both angles. The levels are equal to those of the baseline at $140^{\circ}$, but higher than the baseline at $105^{\circ}$. These higher noy levels lead to the increased PNL of the airfoils over the baseline at the lower directivity angles that is seen in Fig. 5. The behavior of the noy levels near the low frequency hump is different. At $105^{\circ}$ the best airfoil configuration has slightly lower noy levels than the baseline, but the noy levels of the worst

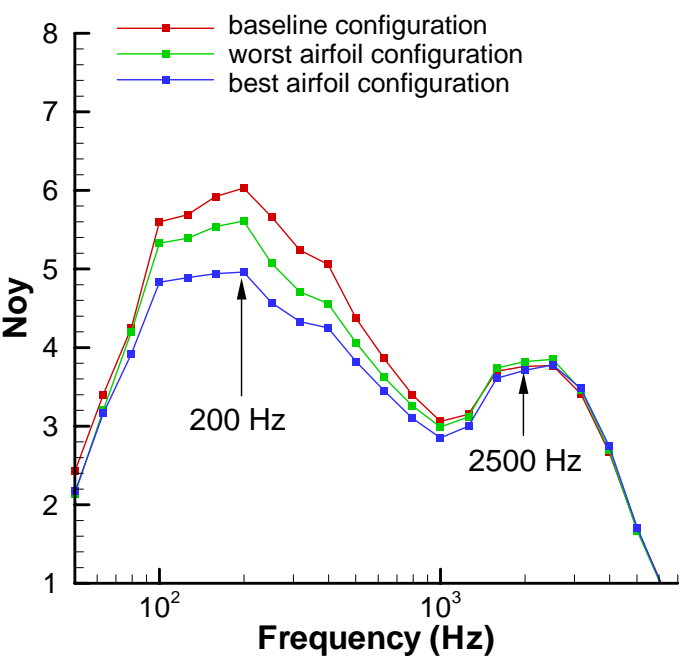

(b)

Figure 6. The noy spectra for observation angles of (a) $105^{\circ}$ and (b) $140^{\circ}$. The legends are the same for both plots. 
configuration are significantly higher. At $140^{\circ}$ both airfoil configurations show lower noys than the baseline, with the significantly lower levels for the best configuration being the main contributor for reducing its EPNL to a value lower than that of the baseline. Hence for the airfoils to reduce effective perceived noise, increases in noy levels in the $400 \mathrm{~Hz}$ band at observation angles near $105^{\circ}$ must be controlled, and large reductions in noy levels in the $200 \mathrm{~Hz}$ band at large observation angles must be achieved.

The one-third octave band levels for the nozzle configurations of Figs. 5 and 6 are shown in Fig. 7. At both the low and high frequencies discussed above, the relative sound pressure levels between the three configurations show the same behavior as the relative noy levels of Fig 6 . Hence it was concluded that the sound pressure level at the frequencies of the PNL humps were appropriate choices for the system responses of the MDOE analyses. An MDOE analysis was performed for the sound pressure levels in the third octave bands at $400 \mathrm{~Hz}$ and $2500 \mathrm{~Hz}$ at the $105^{\circ}$ observation angle, and for the sound pressure levels in the third octave bands at $200 \mathrm{~Hz}$ and $2500 \mathrm{~Hz}$ at the $140^{\circ}$ angle.

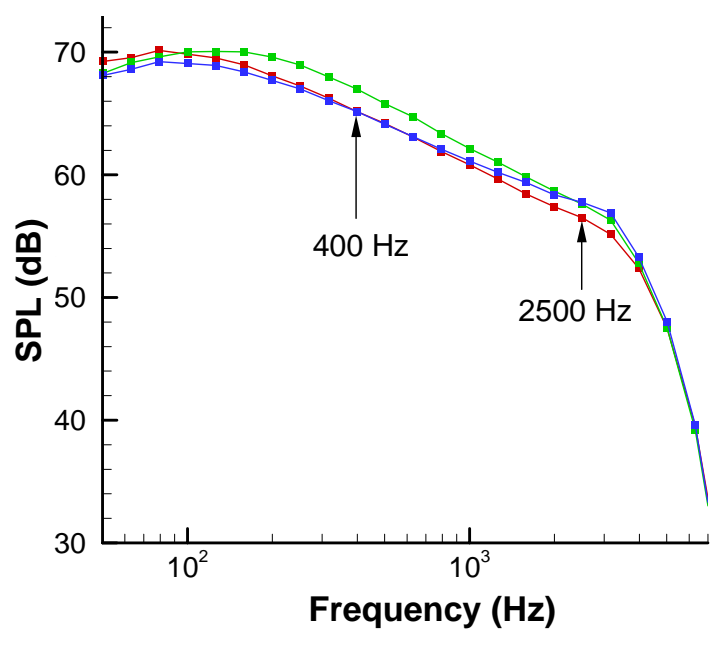

(a)

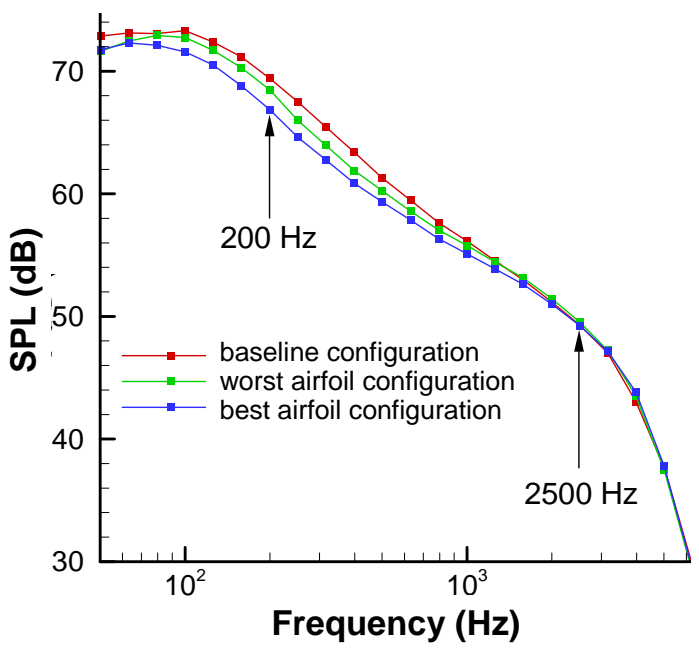

(b)

Figure 7. The one-third octave band levels for observation angles of (a) $105^{\circ}$ and (b) $140^{\circ}$. The legends are the same for both plots.

The MDOE analysis determines a systematic error from repeated data taken at the center point configuration. The one-third octave band levels for the replicated center point data are shown in Fig. 8 along with the baseline data

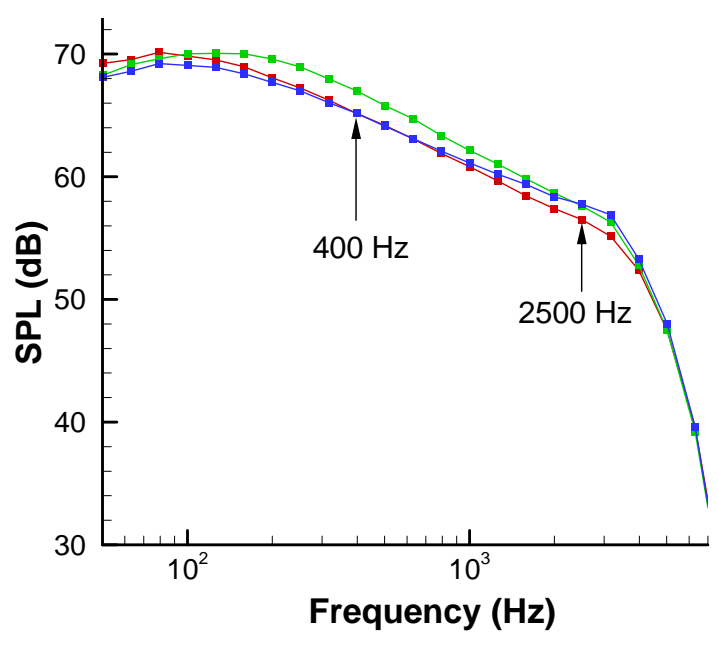

(a)

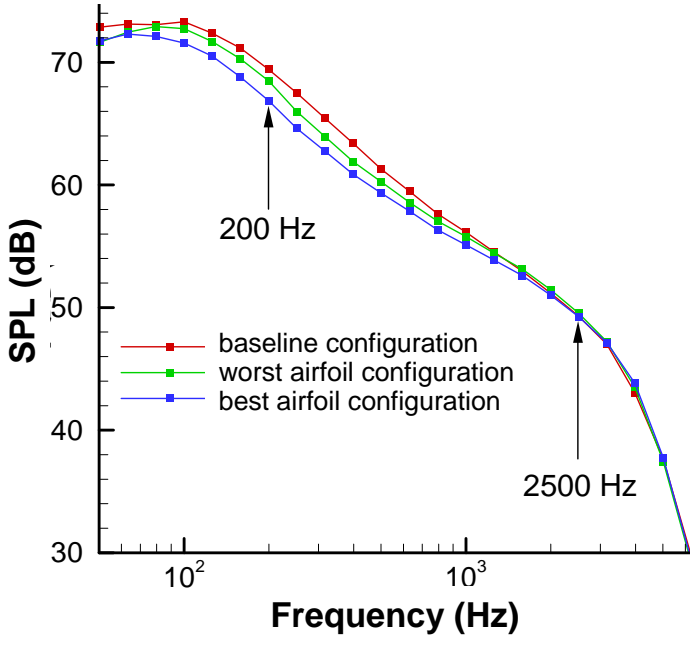

(b)

Fgure 8. The one-third octave band levels for observation angles of (a) $105^{\circ}$ and (b) $140^{\circ}$. The legends are the same for both plots. 
for observation angles of $105^{\circ}$ and $140^{\circ}$. Two runs were taken each of the four test days. Although the center point data repeated reasonably well, blocking effects were identified and accounted for in the MDOE analysis.

As might be inferred from the comparison of the best and worst airfoil configuration noise spectra, all the airfoil configurations tested increased high frequency noise over that of the baseline at $105^{\circ}$. The MDOE analysis showed that none of the variations in the four airfoil factors had any significant effect on the band noise level, so altering the vane configuration had no impact on the noise generation. An MDOE analysis of the high frequency noise at $140^{\circ}$ also showed no impact of altering the vane configuration. This was not true for the low frequency noise.

The results of the MDOE analysis using the sound pressure levels in the $400 \mathrm{~Hz}$ band at an observation angle

Table 3. Model for the $400 \mathrm{~Hz}$ and $105^{\circ}$

\begin{tabular}{|l|c|c|c|}
\hline Major Effect & & Confidence (\%) & Coefficient \\
\hline A & AOA & $>99.99$ & 0.42 \\
\hline C & Axial Top & $>99.99$ & -0.33 \\
\hline$S P L_{105^{\circ}, 400 \mathrm{~Hz}}=65.91+0.42 * A-0.33^{*} \mathrm{C}$ \\
\hline
\end{tabular}
$105^{\circ}$ as the system response are shown in Table 3. The major effects contributing to the sound pressure level in this band are found to be the angle of attack and the axial location of the top airfoils, factors A and C, respectively. There is a $99.99 \%$ confidence level that the sound pressure level changes are the result of changes in the two main effects rather than experimental error. The equation for the sound pressure level and the coefficients obtained from the linear regression model (see Table 3) assume that factors are coded which means that a value of -1 is used for the lower limit and a value of 1 is used for the upper limit. (For example, a value of -1 is used for a $5^{\circ}$ angle of attack and a value of 1 is used for a $10^{\circ}$ angle of attack.) The signs of the coefficients indicate that the sound pressure level increases with increasing angle of attack and decreases as the top airfoils are moved upstream. The relative magnitudes of the coefficients indicate that changing the angle of attack has a slightly greater impact on the sound pressure level than changing the axial location of the top airfoils. If significant curvature is not detected in the analysis, the equation for sound pressure level may be used for all factor levels between the high and low levels in Table 1.

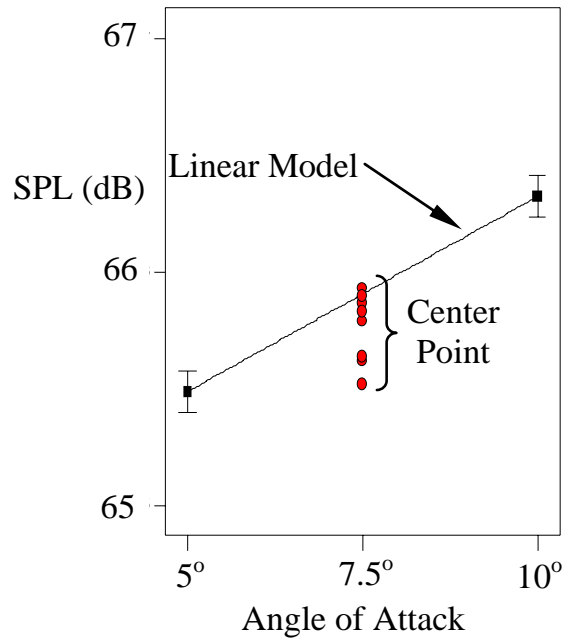

Figure 9. A plot of the sound pressure level in the $400 \mathrm{~Hz} 1 / 3$ octave band as a function of angle of attack obtained from the MDOE analysis for an observation angle of $105^{\circ}$ and the top vanes located at the 0.5 axial position.

A plot of the calculated sound pressure level from the equation in Table 3 as a function of angle of attack is shown in Fig. 9. The replicated center points in the design are shown in red. The offset of the center points from the value predicted by the linear model indicates that significant curvature occurs and the linear model may not sufficiently predict the sound pressure levels for points other than those tested in the experiment. Additional points would need to be added to the design to quantify the curvature and enhance the model.

The results of the MDOE analysis using the sound pressure levels in the $200 \mathrm{~Hz}$ band at an observation angle of $140^{\circ}$ as the system response are shown in Table 4. All of the main factors selected for the experiment and two interactions (AC and BD) impact the sound pressure level. Interactions indicate that the effect on the sound pressure level from changing one of the factors in the interaction (A for the AC interaction) depends on the level of the other factor ( $\mathrm{C}$ in the AC interaction). For the AC interaction, the impact of changing the axial location of the top airfoils when the airfoil angle of attack is large is different than changing the axial location of the top airfoils when the airfoil angle of attack is small, as shown by the interaction plot in Fig. 10. Increasing the angle of attack for $\mathrm{C}=0.75$ has a much greater effect on the sound pressure level than for $\mathrm{C}=0.25$. The confidence levels for all of the factors (and interactions) shown in Table 4 are greater than $94 \%$. The relative magnitudes of the

Table 4. Model for the $200 \mathrm{~Hz}$ and $140^{\circ}$

\begin{tabular}{|l|c|c|c|}
\hline Major Effect & & Confidence (\%) & Coefficient \\
\hline $\mathrm{A}$ & AOA & $>99.99$ & -0.33 \\
\hline $\mathrm{B}$ & Azimuthal Angle & 99.6 & 0.22 \\
\hline $\mathrm{C}$ & Axial Top & $>99.99$ & -0.28 \\
\hline $\mathrm{D}$ & Axial Bottom & $>99.99$ & 0.36 \\
\hline $\mathrm{AC}$ & Interaction & 94.89 & -0.10 \\
\hline $\mathrm{BD}$ & Interaction & 96.55 & -0.11 \\
\hline $\mathrm{SPL}$ & $=67.63-0.33 * A+0.22 * B$ \\
$-0.28 * \mathrm{C}+0.36 * D-0.10 * A C-0.11 * B D$ \\
\hline
\end{tabular}
coefficients indicate that the individual factors have a greater impact on the sound pressure level than the interactions. The sign of the coefficient for the angle of attack indicates that increasing the angle of attack decreases the low frequency, a result contrasting that obtained for low frequency noise near $105^{\circ}$. Moving the top airfoils upstream and the bottom airfoils downstream decreases noise. Analysis of the flow field data acquired during the test is required to understand better the impact of airfoil axial location on the resulting noise (see Section V). No significant curvature was 
identified in the analysis, making it possible to predict the effect on the sound pressure level due to combinations of the factors.

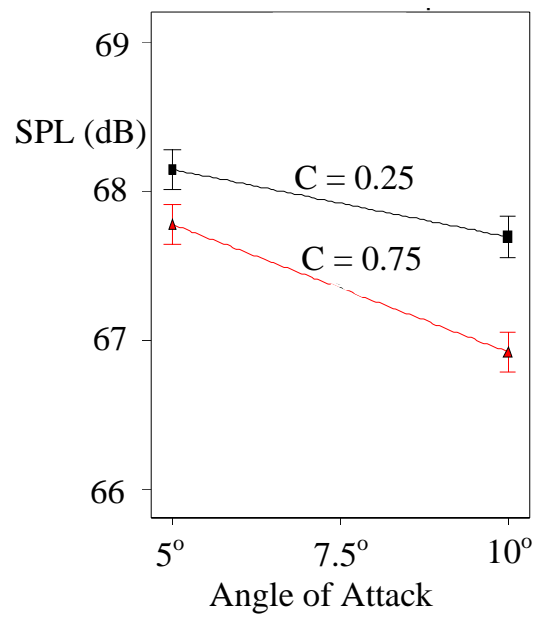

Results from an optimization study to determine the vane configurations that minimize the low frequency noise at observation angles of both $105^{\circ}$ and $140^{\circ}$ is shown in Table 5. The results were obtained using the models shown in Tables 3 and 4 that were obtained from the MDOE analysis. The factor levels and predicted sound pressure levels are shown in the Table. (Note the predicted sound pressure levels in the $400 \mathrm{~Hz}$ band at $105^{\circ}$ may not accurately reflect what would be measured in experiments due to the curvature identified in the analysis.)

Table 5. Optimized Designs for Minimizing Low Frequency Noise

Figure 10. The AC interaction plot showing the change in sound pressure level in the $200 \mathrm{~Hz}$ band at an observation angle of $140^{\circ}$. Factor $B$ is equal to $60^{\circ}$ and factor $\mathrm{D}$ is equal to 0.50 .

\begin{tabular}{|c|c|c|c|c|c|}
\hline AOA & Azimuthal & Axial Top & Axial Bottom & $\mathbf{1 0 5}^{\mathbf{0}}, \mathbf{4 0 0} \mathbf{~ H z}$ & $\mathbf{1 4 0}^{\mathbf{}}, \mathbf{2 0 0} \mathbf{~ H z}$ \\
\hline 6.63 & 50.00 & 0.75 & 0.25 & 65.43 & 66.81 \\
\hline 5.83 & 50.25 & 0.75 & 0.25 & 65.29 & 66.96 \\
\hline 6.10 & 50.00 & 0.75 & 0.26 & 65.34 & 66.92 \\
\hline 7.49 & 50.03 & 0.75 & 0.25 & 65.57 & 66.66 \\
\hline 5.05 & 50.00 & 0.69 & 0.25 & 65.25 & 67.13 \\
\hline 8.59 & 52.62 & 0.75 & 0.25 & 65.75 & 66.56 \\
\hline 5.00 & 50.30 & 0.75 & 0.34 & 65.15 & 67.26 \\
\hline 8.45 & 59.88 & 0.75 & 0.25 & 65.73 & 66.82 \\
\hline 9.60 & 50.00 & 0.75 & 0.39 & 65.92 & 66.56 \\
\hline 9.46 & 60.74 & 0.75 & 0.43 & 65.90 & 66.93 \\
\hline
\end{tabular}

\section{B. MDOE Results for Takeoff Conditions with No Forward Flight}

The same type of analysis was performed for the takeoff condition with no forward flight that was presented for $\mathrm{s}$ flight Mach number of 0.2. The perceived noise levels for the best and worst airfoil configurations and for the baseline nozzles are shown in Fig. 11. The introduction of the vanes increased the perceived noise levels at

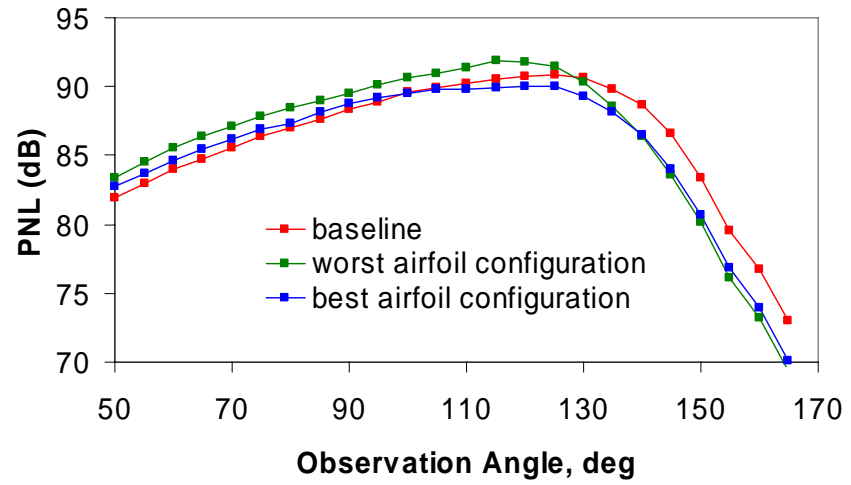

Figure 11. The pnl levels for the best and worst airfoil configurations and the baseline nozzles. upstream and broadside angles and reduced perceived noise in the direction of the peak jet noise. The vanes also result in a shift of the peak pnl angle from that of the baseline. The MDOE analysis will use the band levels that significantly impact the noy levels near the peak PNL angle $\left(125^{\circ}\right)$ and at an angle of $145^{\circ}$ where the vanes appear to have a large impact on the radiated noise.

The noy spectra for the nozzles in Figure 11 are shown in Fig. 12 for observation angles of $125^{\circ}$ and $145^{\circ}$, respectively. The low frequency peak $(200 \mathrm{~Hz}$ band) for an observation angle of $125^{\circ}$ has a much greater impact on the perceived noise than the high frequency peak at $2500 \mathrm{~Hz}$ and, therefore, only the one-third octave band levels in the $200 \mathrm{~Hz}$ band was used for the MDOE analysis. For $145^{\circ}$ the dominant peak in the noy spectrum is at $100 \mathrm{~Hz}$ so this band will be used for the second MDOE response.

The results of the MDOE analysis are shown for the $125^{\circ}$ angle in Table 6. Decreasing the azimuthal angle, moving the top airfoils upstream, and moving the bottom airfoils downstream decreases the sound pressure level in the $200 \mathrm{~Hz}$ band. The impact of the B, C, and D factors on the sound pressure level in Table 6 is similar to that observed for large observation angles at a flight Mach number of 0.2 (see Table 4).

The results for the MDOE analysis at an observation angle of $145^{\circ}$ are given in Table 7. Increasing the angle of attack and moving the airfoils downstream decreases the sound pressure level in the $100 \mathrm{~Hz}$ band. The impact of the A and D factors is similar to that for the forward flight case at an observation angle of $140^{\circ}$ although the model in Table 7 has been greatly simplified from that in Table 4 . There was no curvature identified in the MDOE analysis and, therefore, the models in Tables 6 and 7 can be used for factor levels between those shown in Table 1. 


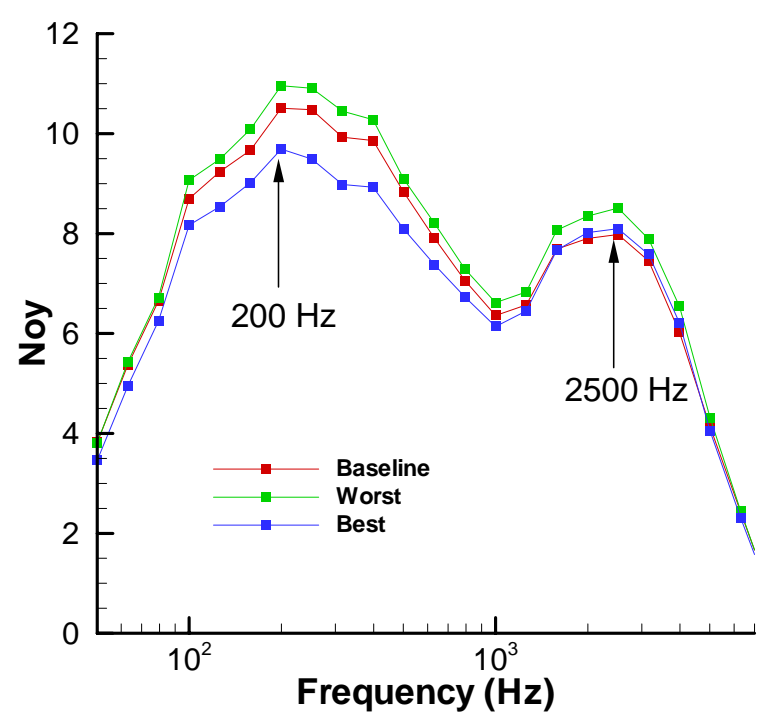

(a)

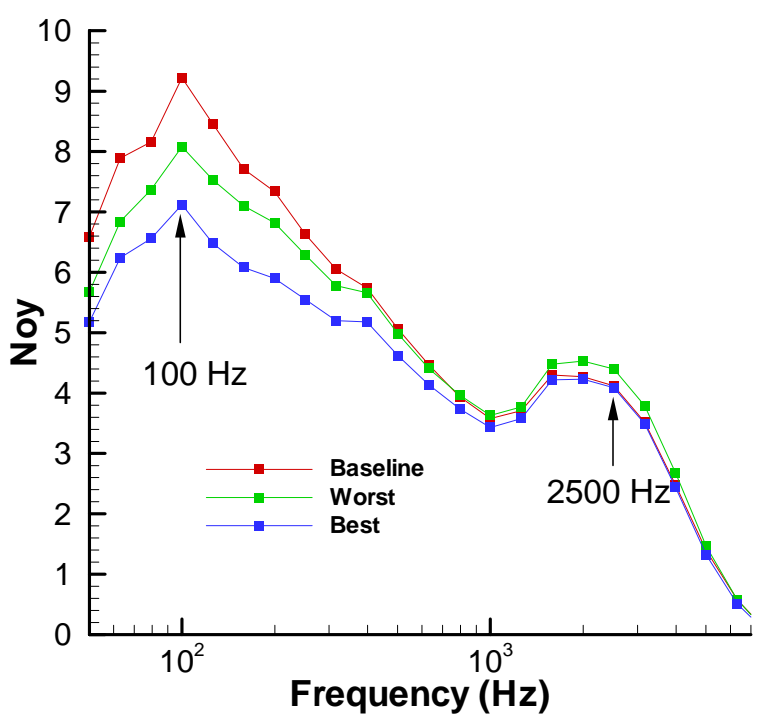

(b)

Figure 12. The noy spectra for observation angles of (a) $125^{\circ}$ and (b) $145^{\circ}$. The legends are the same for both plots.

Table 6. Model for $200 \mathrm{~Hz}$ and $125^{\circ}$

\begin{tabular}{|l|c|c|c|}
\hline Major Effect & & Confidence (\%) & Coefficient \\
\hline B & Azimuthal Angle & $>99.99$ & 0.55 \\
\hline C & Axial Top & 99.81 & -0.30 \\
\hline D & Axial Bottom & 99.59 & 0.27 \\
\hline \multicolumn{3}{|c|}{$S P L_{125^{\circ}, 200 \mathrm{~Hz}}=76.51+0.55^{*} B-0.30 * C+0.27 * D$} \\
\hline
\end{tabular}

\section{BPR 5 Nozzle System}

Only a single vane configuration was tested on the BPR 5 nozzle system at representative takeoff conditions and a forward flight Mach number of 0.20 . The angle of attack of the top two airfoils was $15^{\circ}$ and the angle of attack of the bottom two airfoils was $10^{\circ}$. The axial location of the top and bottom airfoils was 0.5. The airfoil azimuthal angle was $70^{\circ}$.

The perceived noise levels for the baseline nozzle and the nozzles with vanes are shown in Fig. 13. As in the

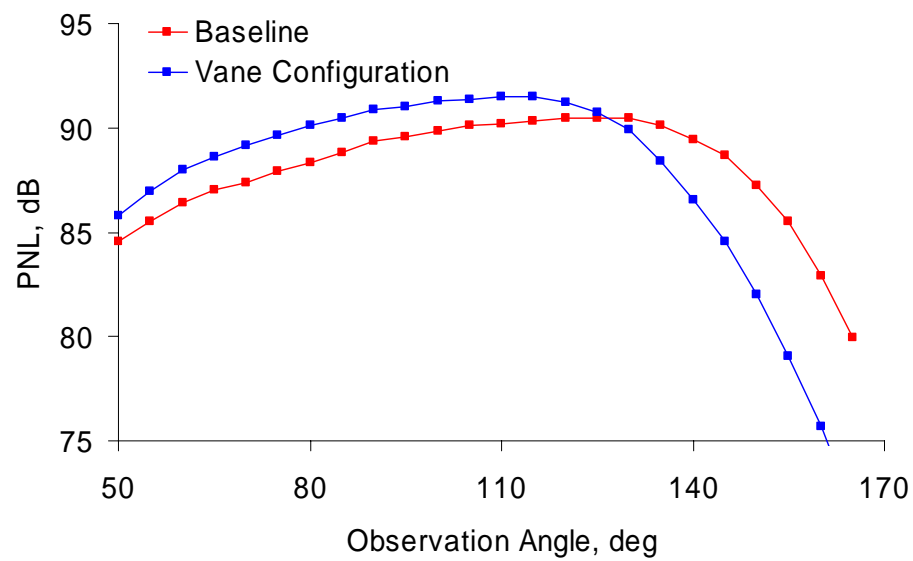

Figure 13. The perceived noise levels for the baseline nozzle and the vane nozzle.
Table 7. Model for $100 \mathrm{~Hz}$ and $145^{\circ}$

\begin{tabular}{|c|c|c|c|}
\hline Major Effect & & Confidence (\%) & Coefficient \\
\hline $\bar{A}$ & $\overline{\mathrm{AOA}}$ & $>99.99$ & -0.84 \\
\hline D & Axial Bottom & $>99.99$ & 0.43 \\
\hline
\end{tabular}
case of the BPR 8 data, the application of the vanes increases the perceived noise levels at upstream and broadside angles to the jet and decreases perceived noise levels in the peak jet noise direction. However, the peak pnl angle is further downstream for the BPR5 model than for the BPR 8 model, so the resulting effective perceived noise level reduction from that of the baseline nozzle is larger, equal to 1.0 EPNdB.

The noy spectra for observation angles of $115^{\circ}$ (peak pnl angle) and $145^{\circ}$ are shown in Figs. 14 (a) and (b), respectively. As in the case of the BPR 8 model, the vanes elevate high frequency noise levels near at the peak pnl angle and reduce low frequency noise levels near the peak jet noise angle when compared to the baseline nozzle. The increase in low frequency noise at $115^{\circ}$ for the 
vane nozzle over that of the baseline nozzle may be the result of a poor vane configuration. However, it is not possible to determine the impact of the vane configuration on the radiated noise from a single test configuration.

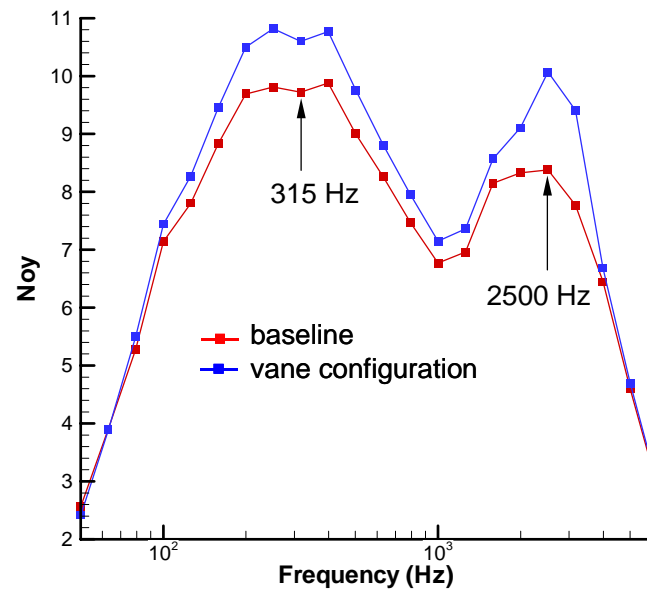

(a)

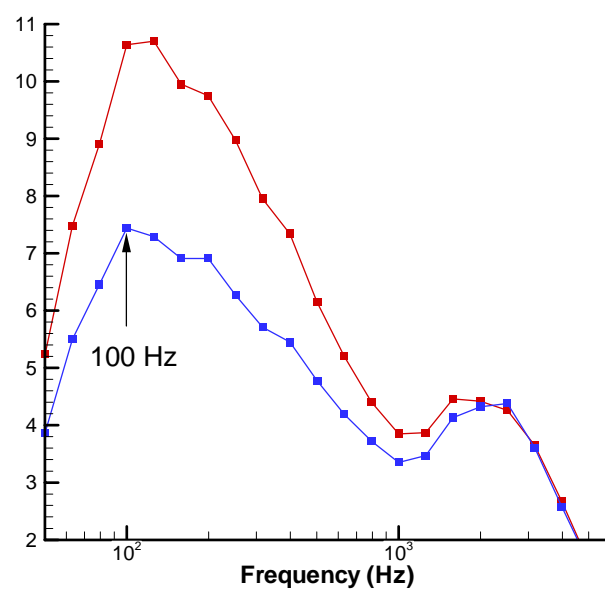

(b)

Figure 14. The noy spectra for observation angles of (a) $115^{\circ}$ and (b) $145^{\circ}$. The legend is the same for both plots

\section{Discussion and Conclusions}

The introduction of vanes to the fan stream of a coannular jet increases high frequency noise at upstream and broadside observation angles. Vanes with large angles of attack can also lead to increases in low frequency noise at these observation angles. The vane configuration appears to only impact the low frequency noise.

The benefit of placing vanes in the fan stream is in the large, low frequency noise reductions that can occur at observation angles in the peak jet noise direction. The low frequency noise can be significantly reduced with the proper selection of vane configuration. Vanes with large angles of attack reduce low frequency noise at these observation angles. The axial location of the airfoils is also a critical parameter in reducing the radiated noise.

The effect of the vanes on the perceived noise levels and the effective perceived noise levels depends on the operating condition, the forward flight Mach number, the engine bypass ratio, and the scaling factor used to scale the model data to full scale. The operating condition, forward flight Mach number, and engine bypass ratio determine the observation location for the peak pnl. Increasing the forward flight Mach number tends to move the peak pnl angle in the upstream direction to locations where the vanes tend to be less effective at reducing noise. Decreasing the engine bypass ratio tends to move the peak pnl angle in the downstream direction where the vanes are more effective at reducing noise. Changing the scaling factor may result in shifting the high frequency noise to regions where the impact of the vanes on the noy levels is minimal.

Preliminary results from particle image velocimetry (PIV) studies show that the vanes have a greater impact on the flow than simply altering the length of the secondary potential core (which impacts low frequency noise radiated in the peak jet noise direction). The vane angle of attack and axial location affect the length of the primary potential core, distort the fan stream, and affect vorticity levels in the flow just downstream of the core nozzle trailing edge. A careful analysis of the PIV data must be performed to relate the vane parameters to the resulting jet noise characteristics.

\section{Acknowledgments}

The authors thank the engineers and technicians in the AAPL for assisting with the experiments. The authors also thank Clifford Brown for assistance with data processing. 


\section{References}

${ }^{1}$ Bridges, J., and Brown, C., "Parametric testing of chevrons on single flow hot jets," AIAA-2004-2824, 2004.

${ }^{2}$ Martens, S., "Jet noise reduction technology development at GE Aircraft Engines," ICAS 2002 Congress 842.1 - 842.10, 2002.

${ }^{3}$ Janardan, B. A., Hoff, G. E., Barter, J. W., Martens, S., Gliebe, P. R., Mengle, V., and Dalton, W. N., "AST critical propulsion and noise reduction technologies for future commercial subsonic engines," NASA/CR-200210039, 2000.

${ }^{4}$ Henderson, B., Kinzie, K., Whitmire, J., and Abeysinghe, A., "Impact of fluidic chevrons on jet noise," AIAA2005-2888, 2005.

${ }^{5}$ Greska, B., and Krothapalli, A., "Jet noise reduction using aqueous microjet injection,” AIAA-2004-2971, Manchester, U.K., 2004.

${ }^{6}$ Papamoschou, D., "New method for jet noise reduction in turbofan engines," AIAA J., Vol. 42, No. 11, 2004, pp. $2245-2253$.

${ }^{7}$ Tam, C. K. W., “Jet noise:since 1952,” Theoret. Comput. Fluid Dynamics, Vol 11, 1988, pp. 393 - 405.

${ }^{8}$ Crighton, D. G., and Huerre, P., "Shear-layer fluctuations and superdirective acoustic sources," J. Fluid Mech., Vol 220, 1990, pp. 355 - 368.

${ }^{9}$ Papamoschou, D., and Nishi, K., "Jet noise suppression with fan flow deflectors in realistic-shaped nozzle," AIAA-2005-993, 2005.

${ }^{10}$ Papamoschou, D., "Parametric study of fan flow deflectors for jet noise suppression,” AIAA-2005-2890, 2005.

${ }^{11}$ Montgomery, D., Design and Analysis of Experiments, John Wiley \& Sons, New York, 1997.

${ }^{12}$ Bridges, J., "Measurements of turbulent flow field in separate flow nozzles with enhanced mixing devices-test report," NASA TM-2002-211366, 2002.

${ }^{13}$ Ahuja, Testor, and Tanna, "The free jet as a simulator of forward velocity effects on jet noise", NASA CR 3056, 1979.

${ }^{14}$ "Acoustics--Attenuation of sound during propagation outdoors--Part I: Calculation of the absorption by the atmosphere," International Standard ISO 9613-1:1993 (International Organization for Standardization, Geneva, Switzerland, 1993). 